DoI: http://dx.doi.org/10.11157/sites-vol14iss2id38o

\title{
NARRATING AGENCY AND CONSTRUCTING COMMUNITY: COMMONALITIES AND TENSIONS IN HEALTH TECHNOLOGY NARRATIVES
}

\author{
Claire Black ${ }^{1}$
}

\begin{abstract}
Contemporary biological and digital health technologies disrupt people's bodies and lives in various ways. One significant way in which people respond to this disruption is by narrating stories about their lives and how these technologies fit within them. This theme of storytelling appears repeatedly across ethnographic explorations of specific health technologies, yet there has been little exploration of the significance of how this plays out comparatively across different technologies. I draw upon ethnographic studies of three health technologies - cadaveric organ donation, commercial surrogacy, and self-tracking digital health technologies - to analyse some common threads of these 'health technology narratives'. Narrative forms differ across the technologies and different groups of users, but these stories all position their subjects as agentive in the face of these challenges. However, when even seemingly empowering narratives become hegemonic within a community of users, this can also marginalise users of these technologies whose experiences do not conform.
\end{abstract}

Keywords: health technologies; narratives; organ transplantation; surrogacy; quantified self.

\section{INTRODUCTION}

Throughout history, technologies have reconfigured how humans experience their bodies, enhancing their abilities and challenging their boundaries. In some respects, contemporary biological and digital health technologies such as new reproductive technologies, organ transplantation technologies, and digital monitoring devices are just the latest iteration in this long tradition. Yet in others, these technologies which allow exchanges of body parts and of babies, the conversion of death into life and of bodies into bytes, seem to fragment bodies, blur boundaries, and redefine relationships in unprecedented ways. As a result, 
the people using these technologies must construct new understandings of their bodies and lives that allow for these changes.

One significant way in which people do this is by narrating stories about their lives and how these technologies fit within them. This theme of storytelling appears repeatedly across ethnographic explorations of specific health technologies (Berend 2016; Butterfield 2012; Hsieh 2004; Ragoné 1994; Sharp 2006; Teman 2010), yet there has been little exploration of how this plays out comparatively across different technologies. I draw upon ethnographic studies of three diverse examples of biological and digital health technologies - cadaveric organ donation, commercial surrogacy, and self-tracking digital health technologies - to analyse some common threads of these 'health technology narratives'. I also focus primarily on these technologies in a United States (US) context. This is not necessarily representative of how these technologies get taken up and of the stories that are told elsewhere, with organ transplantation and surrogacy especially impacted by different legislative contexts and cultural understandings of concepts like death and kinship. Nonetheless, the influential and leading role of the US in the use of these technologies makes it a particularly interesting place to analyse these dynamics.

In explaining surrogacy narratives, Zsuzsa Berend $(2016,28)$ suggests that surrogacy experiences elicit stories because they are a 'breach of the ordinary'. In this way, these stories echo other types of personal narrative that have been studied previously (Becker 1998; Frank 1995). Building upon anthropological theorising of illness narratives and narratives of political violence, I suggest that it is the disruptive novelty of these technologies - to assumptions about the life course, bodily boundaries, kinship and reproduction, and ways of understanding bodies - that calls for new stories capable of making sense of these experiences. Although the common narrative forms differ across the technologies and groups, these stories all position their subjects as agentive in the face of these challenges. However, when even seemingly empowering narratives become hegemonic within a given community, this can also marginalise users of these technologies whose experiences do not conform. I argue that it is important to take seriously both these health technology narratives and this tension in their role in the lives of health technology users.

\section{BACKGROUND ON THE TECHNOLOGIES}

Organ transplantation describes any transfer of an organ from a donor body to a recipient whose own organ is missing or damaged. Although this covers several different types of organ transfer, I focus upon cadaveric human trans- 
plantation: the transfer of organs from a human donor who has been declared 'brain-dead' but whose body is maintained on a respirator to keep their organs viable until they can be procured and transplanted into another human recipient (Sharp 2006, 4). As this form of transplantation has become increasingly common, it offers a larger number of seriously ill patients a chance at survival. However it also forces people to grapple with a situation which would have previously been impossible: the existence of a dead person's organ within the recipient's body. In the US, while living donors are frequently related to or otherwise known to the recipient, cadaveric donors are always initially anonymous strangers whose kin decide to allow the donation of their organs (Sharp $2006,13)$. As cadaveric donation became more popular in the US, transplant staff started to require both parties to remain anonymous, on the basis that this protected privacy and prevented the development of pathological feelings of guilt or identification with the donor on the recipient's part (Fox and Swazey 1992, 37; Sharp 2006, 106). However, some recipients and donor kin decide to defy such rules of anonymity, find each other, and establish relationships, further complicating the impact of these technologies on the bodies and people involved (Sharp 2006, 161).

Surrogacy arrangements are those in which a surrogate becomes pregnant with the intention that the child will be raised by another person or couple. ${ }^{2}$ Surrogacy as a contemporary commercial enterprise in the US has arisen following developments in assisted reproductive technology since the 1970s, including the emergence of commercial sperm banks and development of in vitro fertilisation (IVF). There are two distinct types of surrogacy - traditional and gestational - each of which poses its own challenges to naturalised Western understandings of kinship and reproduction (Ragoné 1994; Strathern 1992). In traditional surrogacy, the surrogate is artificially inseminated either by sperm of an intended father or by donor sperm, and she is genetically related to the child that she carries but does not intend to raise. In gestational surrogacy, embryos are produced via IVF and then implanted into the surrogate. If intended parents can supply their own ova and sperm, the child will be biologically related to both of them. When this is not possible, donor eggs or sperm will be used instead, and the surrogate remains unrelated to the child (Merino 2010, 17-19). As IVF has become more reliable, gestational surrogacy has become increasingly popular (Berend 2016, 25). These arrangements foreground women's bodies, most obviously the surrogate's, but also that of the intended mother as well as the relationship between the two women. ${ }^{3}$

Broadly speaking, self-tracking is the intentional collection of information about oneself with the aim of using it to improve one's life (Lupton 2016, 2). 
However, digital health technologies such as smartphone apps and wearable digital devices, which allow for the automation of self-tracking practices and a degree of data collection and analysis that was previously unfeasible, have only become popular in the last decade or so (Butterfield 2012, 15; Ruckenstein and Pantzar 2015, 5). As a result, there is relatively little ethnographic research to date on how people utilise these technologies. The one exception to this is the Quantified Self (QS), which has been subject to ethnographic study by several researchers in the recent years (Alkhatib 2014; Butterfield 2012; Nafus and Sherman 2014; Sharon 2016).

The Quantified Self movement was started in 2007 by Gary Wolf and Kevin Kelly, two editors of Wired magazine. The two men were interested in how people were increasingly using new technologies to gain data about themselves and their behaviours in ways that were previously impossible. They decided to start a blog covering topics related to self-tracking, and soon also decided to hold the first 'QS Meetup.' These meetups allowed people who were interested in these issues to come together and talk about their own experiences applying technology to their lives (Butterfield 2012, 8-12). From these initial meetups in San Francisco, the movement spread first across the US and then to other countries. The Quantified Self movement today consists of loosely affiliated local communities of people with an active interest in self-tracking, encapsulated by the Quantified Self tagline 'self-knowledge through numbers' (Butterfield 2012, 53). This is not exclusively focused on health - people may also monitor things like their productivity or finances (Butterfield 2012, 31) - however it is health and bodily monitoring upon which I focus. As people who have made self-tracking a significant part of their lives, Quantified Selfers are not necessarily representative of the broader diffusion and more casual usage of digital health technologies. Nevertheless, their practices speak to how these forms of bodily monitoring might refigure conceptualisations of the self.

\section{DISRUPTION AND STORYTELLING}

When faced with intensely disruptive experiences such as illness and political violence, people make sense of these upheavals through narratives (Becker 1998; Charmaz 1999, 231-232; Das 2007; Eastmond 2007; Frank 1995, 2; Garro and Mattingly 2000, 17; Hunt 2000, 88; Jackson 2002; Trnka 2008, 14). Gay Becker $(1998,61)$ notes that prevalent discourses in the US suggest that life should proceed in an ordered and continuous manner. When people encounter disturbances to this sense of continuity, their identity and sense of normalcy can be challenged (Becker 1998, 30). They therefore tell stories about themselves to try to convey their distress to others and to integrate the disruptive 
experience into their life (Becker 1998, 14; Charmaz 1999, 209; Garro and Mattingly 2000, 27; Hsieh 2004, 40; Hunt 2000, 88). By narrating the disruption as one component of a broader plot, storytellers can construct a sense of overarching coherence and order to events (Becker 1998, 27; Ochs and Capps 1996). These storytellers draw on narrative structures, metaphors and ideologies from their surrounding cultural contexts to achieve this (Becker 1998, 195; Garro and Mattingly 2000, 14; Kleinman 1988, 49).

Organ transplantation, surrogacy and the Quantified Self all involve varying forms of disruption to the lives and bodies of those involved. The stories of organ recipients are those which hew most closely to traditional illness narratives. These individuals live with serious illness prior to their transplant, and storytelling is a tool that can help them make sense of these experiences of illness, transplant surgery and subsequent recovery (Sharp 2006, 106-107). Meanwhile, donor kin are faced with making meaning out of the loss of their loved one, deaths which are frequently sudden and unexpected. Surrogacy offers an alternative path to parenthood for couples who have already experienced the disruption of infertility (Becker 1998, 62). It allows for the conception and pregnancy to still be driven by actions of the intended parents, and often allows for at least one parent to be genetically related to the potential child. However, surrogacy also continues to challenge dominant cultural scripts about reproduction and kinship by fragmenting a previously unified conception of motherhood into biological and social components (Strathern 1992, 27-28). It is against this background that both surrogates and intended parents - and especially intended mothers - use storytelling to construct new understandings of pregnancy and reproduction (Teman 2010, 4). For some Quantified Selfers, it is the impact of a health problem that motivates them to take up self-tracking (Butterfield 2012, 64). However, QS members may also view the self-tracking practices themselves as disruptive in a more positive sense: as offering innovative ways of understanding one's self, body and health, and challenging received scientific and medical authorities (Sharon 2016, 1518). This different type of disruption still calls for stories in which Quantified Selfers make sense of their tracking practices and the data they produce. These different manifestations of disruption shape the different contexts for storytelling, which in turn shapes the plot structures that predominate in the different groups' narratives.

COMMON PLOTS: MIRACLES, HEROISM AND EXPERIMENTATION

Becker $(1998,27)$ argues that narratives of disruption share a common plot in which 'a disruption to life is followed by efforts to restore life to normal'. 
However, all three health technologies discussed here have at least the potential to permanently change the lives of those involved, so such normalising may require significant reconstruction of identity. The differences in how these experiences and resulting identity changes take place manifest in the different plots which are common to the stories of the different groups involved.

Both intended mothers and organ recipients commonly tell stories that contain themes of miracles and rebirth. Intended mothers tell 'miracle stories' about their child's origins (Teman 2010, 202). These frequently begin with a symbolic death which marks the mother's inability to carry their own pregnancy. It is then through the destined surrogacy journey that she is brought back to life: intended mothers describe cosmic signs that showed them that surrogacy was the right path, having immediate chemistry with their surrogates, and miraculous events during the pregnancy, which the mothers identified as messages from God that this was meant to be (Teman 2010, 202-203). Through photo albums, mothers create visual narratives that supplement these verbal ones: these include ultrasound pictures, and photos of the newborn and of the parents holding the baby, but exclude identifiable photos of the pregnant surrogate (Teman 2010, 201). Through these narratives, mothers credit the success of the pregnancy to their own faith and determination to have a child, and the surrogate's role is minimised to an instrumental one (Goslinga-Roy 2000, 125; Teman 2010, 202). Intended parents, and especially intended mothers, tell stories that reinforce their own identities as the child's parents and downplay ways that the surrogate could threaten the exclusivity of these identities. Faith, determination and fate come to replace the experience of pregnancy as the basis for parenthood.

Rebirth is even more stressed in the public testimonials of organ recipients. In this form of storytelling, recipients describe their experience of illness, their wait for an organ, and their subsequent transplant and 'rebirth', before finally thanking their donor and emphasising the importance of organ donation (Sharp 2006, 110-111). These recipients often express having found a 'new lease on life' (Siminoff and Chillag 1999, 37) and many continue to celebrate the anniversary of their transplantation as a second birthday ( $\mathrm{dahl} 2013,138$; Wainwright 2011, 99). Lesley Sharp $(2006,111)$ notes that this narrative structure very closely resembles that of twelve-step programs such as Alcoholics Anonymous. Despite the many differences between the two groups, they share two significant commonalities: like alcoholics, recipients consider being an organ recipient a central and everlasting part of their identity and members of both groups consider themselves survivors who must actively work to maintain their health (Sharp 2006, 112-3). This idea of acquiring a new - and 
permanent - identity speaks to the significance of the rebirth theme for both recipients and intended parents.

Surrogate and donor kin narratives instead emphasise the heroism of the surrogate and donor respectively. Surrogates frequently narrate their experiences of surrogacy as journeys or tests of their character in which they face the risks and challenges of pregnancy and overcome these obstacles to help their intended parents make a family (Berend 2016, 28-29; Teman 2010). Ely Teman further suggests surrogates' journeys can be understood using Joseph Campbell's (1968) model of 'the hero's journey'. This model is theorised as a universal mythic structure in which a hero receives a call to adventure and departs from their ordinary life; enters a new world in which they will carry out their quest; overcomes various trials; and if they succeed, returns to their life having gained knowledge and experience. Teman (2010, 264-265) maps each of these stages onto the experiences in surrogate narratives: the woman learns about surrogacy and puts her ordinary life on hold to undertake the process; enters the new reality of surrogate pregnancy; faces obstacles such as embryo transfer; and after successfully delivering the baby she returns to her ordinary life and retells the story of this quest to others such as journalists or surrogacy support groups.

Donor kin stories do not map as neatly onto the hero's journey, but they do similarly present the donor as heroic. These narratives commonly begin with a description of the donor's life and their relationship to the storyteller, followed by narration of the donor's tragic and often sudden death, and then by explanation of the donation decision and the struggles involved (Sharp 2006, 139). Anja Jensen $(2010,67,77)$ suggests that commonplace narratives in which kin present the donor as heroic are comforting for families because they allow them to reconstruct tragic deaths of the donors as meaningful. Organ donation narratives are a way for donor kin to keep the donor's spirit alive by framing the donation as an altruistic act in line with their generous personality. Family members are constructing their new identity as donor kin through their storytelling, but they are simultaneously also constructing a particular heroic identity for their dead loved ones. In both instances, the fact that surrogates and donors are helping others through their actions is made central to their stories and identities.

Quantified Self narratives have a different structure again. Personal presentations at QS meetups are generally expected to answer three questions: 'what did you do?', 'how did you do it?' and 'what did you learn?' (Butterfield 2012, 46; Fiore-Gartland and Neff 2015, 1472; Sharon 2016, 16). These questions frame 
the Quantified Selfers as innovative experimenters who have successfully produced data about themselves. However, as implied in the third question, the data produced by self-tracking is not an end in itself, but rather a means to produce self-understanding (Sharon 2016). Furthermore, the data alone provides only a 'partial story' (Sharon 2016, 23), and that data must be mixed with or recontextualised within the context of self-tracker's subjective understandings of their life to produce a meaningful narrative (Sharon and Zandbergen $2016,9)$. One such example was a speaker at the 2013 Quantified Self Global Conference who presented a graph that he created with a mood-tracking app. He explained that his use of the mood-tracker was a response to his struggle with bipolar disorder and contextualised the high and low points of the six years of graphed data with reference to events in his personal and work life (Sharon and Zandbergen 2016, 10). It is thus through subjective interpretations of data, framed by pre-existing self-narratives, that quantified data can become a Quantified Self (Davis 2013). This speaks to an understanding of the self in which identity is continuously reconstructed through this combining of quantitative data and qualitative understandings (Sharon 2016, 23). Such a view of the self allows for the self-experimentation and self-improvement upon which the Quantified Self movement is premised.

\section{AGENCY THROUGH STORYTELLING}

All the preceding examples of storytelling share a theme of positioning their narrator as agentive: the storytellers describe making choices, undertaking journeys, overcoming obstacles and solving problems. Quantified Selfers tell the stories of how they used technology to identify an illness before their doctors (Sharon 2016, 11), or to improve their lives, however they might define that improvement, in quantifiable ways (Fiore-Gartland and Neff 2015, 1467; Lupton 2013, 28). The intended parents involved in surrogacy use their stories to frame themselves as the agents whose determination and desire led to the birth of their child. The public narratives of organ recipients position them as survivors who have overcome long odds and great suffering. These examples all support Becker's $(1998,25)$ argument that narratives are effective at mediating disruption because they represent the actions - and therefore also agency - of the narrator who is faced with circumstances they cannot fully control. Arthur Frank (1995, 53-56) further suggests that stories do not just describe the self, they are the medium through which a sense of self is created and reaffirmed. Narrators are not just describing an agentive self; they are constructing it through the act of storytelling. 
This construction of agency through storytelling is present across all the groups, but particularly clear in the case of surrogate and donor kin narratives. Writers on surrogacy often recognise that surrogates are structurally constrained by class or gender roles (Ragoné 1994, 62; Teman 2010, 37). They are further restricted by surrogacy contracts, which place greater power in the hands of the intended parents, limit the decisions surrogates can make about their own bodies and subject them to various technologies (Cussins 1998, 54; Ragoné 1994, 47). However, despite these objective constraints, subjective surrogate narratives are often highly agentive (Teman 2010, 237). As well as framing it as a heroic quest, surrogates also describe surrogacy as a 'calling', emphasising both their choice and suitability to undertake surrogacy and downplaying the role of money (Kashmeri 2008, 58). Indeed, surrogacy tends to have little impact on long-term social or economic status for surrogates, yet they do succeed in achieving their quest (Teman 2010, 275). Surrogates also continue to tell their story to media, co-workers or acquaintances long after the event (Ragoné 1994, 80-81; Teman 2010, 277). Frank's $(1995,22)$ argument that 'the truth of stories is not in what was experienced, but equally what becomes experience in the telling and its reception' suggests that it is through the telling itself that surrogates are empowered (Teman 2010, 281-282); through telling her story, the surrogate constructs and reaffirms her sense that she has done something heroic and important, and therefore has something to offer others.

In organ transplantation, health professionals dehumanise donors as they prepare to extract and transplant their organs, disregarding donor kin who perceive such practices as disturbing and disrespectful (Hogle 1995, 206; Sharp $2007,20)$. Yet Sharp $(2006,157)$ suggests that memorialising donor kin narratives have potential to repersonalise the donor and counter professional attempts to render donors as anonymous members of a generic category. She describes a transition from the early 2000 in which donor kin were rarely provided opportunities to speak publicly, to her time of writing when some Organ Procurement Organisations insisted on the right of family members of donors to speak without restrictions (Sharp 2006, 145). Donor families, who felt ignored as a group and objected to the erasure of donor stories from broader transplantation narratives, were instrumental in pushing for this shift (Jensen 2010, 78). By sharing their stories, donor kin both force those involved in transplantation to acknowledge donors as people and allow them to keep their memories of their loved one alive. Once again, it is through the actual telling of stories that both donor kin and the deceased donor are constructed as agentive participants in transplantation. 
Stories do not exist in a vacuum. Storytelling is a 'relational act' in which storytellers not only tell their stories to an audience, but also draw upon experiences and ideas from their social contexts in the process of narrative construction (Charmaz 1999, 231; Garro and Mattingly 2000, 11). Support groups and interest communities are particularly influential in this process, because they serve as spaces in which individuals encounter others who are undergoing similar experiences (Becker 1998, 166-167). In the context of these three health technologies, storytelling contributes to the construction of these communities and these communities in turn shape their members' narratives.

Surrogacy and organ transplantation support groups both allow members to compare experiences with each other and build a sense of group solidarity (Jensen 2010, 67; Kashmeri 2008, 18; Ragoné 1994, 42). Both online and inperson support groups offer an empathetic audience for members' narratives (Teman 2010, 281-282). One member of a support group for organ recipients commented that ' $[\mathrm{i}$ ] t's hard to explain it to anyone else [who hasn't received a transplanted organ] [...] what the person goes through' (Hsieh 2004, 53). This statement demonstrates the idea that having an unusual experience in common allows for greater understanding and sharing within these groups. Berend $(2016,28)$ further argues that narrative exchanges in an online surrogate community are not just about sharing stories, but also collectively creating understandings and making sense of one's experiences through interaction. Elaine Hsieh (2004) similarly demonstrates how this takes place in support groups for organ recipients: stories are told in the context of particular relationships and conversations, and listeners may show an understanding of a speaker's experiences or alternatively may interrupt or challenge story meanings. Through this process of narrative negotiation, a group identity is constructed and people learn how to tell stories as members of that group.

These same dynamics of story sharing and construction of group identity are also expressed in analyses of Quantified Self communities. Tamar Sharon and Dorien Zandbergen $(2016,11)$ suggest that Quantified Selfers constitute a 'confessional community'; like the previously discussed support groups, members feel able to share intimate stories about their health and lives with others in the group. In this instance, rather than shared experience per se, it is the use of a common language of numbers and data that allows these individuals to more readily share stories that might be painful or embarrassing. One such example is a Quantified Selfer who found it much easier to compare the number of times he goes to the bathroom per day with others than to directly tell 
people that he has a bladder problem (Sharon and Zandbergen 2016, 11). By integrating their data into personal stories, self-trackers are able to connect with each other (Fiore-Gartland and Neff 2015, 1472; Sharon 2016, 23). This is not just a matter of sharing stories, but of people helping each other make meaning out of data (Alkhatib 2014, 19; Fiore-Gartland and Neff 2015, 1472). The participant with the bladder problem, for example, uses feedback from others to understand how his personal data compares to a broader sample and thus make meaning of his experiences.

Sharon $(2016,18)$ also suggests that a Quantified Self group identity is constructed through storytelling. She points out that the origin stories of the QS community which are told at meetings emphasise autonomy, defiance and non-conformity. She highlights two examples of individuals held up by Quantified Selfers as 'self-quantifying pioneer[s]': Larry Smarr, who discovered his Crohn's disease through self-tracking despite dismissal by doctors, and Seth Roberts, a former research psychologist who rejected scientific institutions and experts in his self-experimentation. Roberts instead emphasised data-gathering and idea generation, as seen in his self-experiments such as measuring the impact of high butter consumption on cognition (Butterfield 2012, 82). By sharing these stories of 'QS heroes', members emphasise experimentation and self-knowledge as key values within the QS community. It is these same values that are then also incorporated into individual members' personal narratives, demonstrating again the connection between group interaction and identity and members' stories.

\section{DOMINANT NARRATIVES AND MARGINALISED ALTERNATIVES}

While they provide a space for sharing and co-constructing stories, these communities and associated institutions can also serve to normalise certain narratives and silence others. Based on their shared experiences or values, these groups allow members to co-construct ideologies about their bodies and lives which may differ from those of their surrounding society but better fit their circumstances (Becker 1998, 166-167). In this way, such social groups can buffer against experiences of disruption and serve to normalise technology use (Becker 1998, 178). However, by pushing certain acceptable narratives, those who find that their experiences do not conform to these narratives can be doubly marginalised from both their broader society and this social group.

In the Quantified Self movement, this process is driven by the expected narrative format, which requires stories both to be framed as personal narratives and draw upon quantified data. Toolmakers are generally free to present tools 
which they have developed at QS meetings, so long as their presentation conforms to this format of a personal narrative, explaining what drove them to develop the tool and the personal projects that they have undertaken, rather than making a 'sales pitch' (Butterfield 2012, 46). On the other hand, purely personal stories that lack supporting 'hard data' may also be poorly received by QS audiences. In one such instance, a Silicon Valley entrepreneur at a QS meeting told a story of undertaking an unusual diet, one that he argued had improved his physical and mental health, but he was shut down by the moderator for his absence of supporting data (Alkhatib 2014, 14). This participant seemed to have the same goal as other Quantified Selfers, yet his narrative was rejected for not conforming to the normative QS structure. Potential members must therefore adapt to dominant narrative formats and values if they wish to remain engaged in the movement. Those who do not wish to follow these conventions can, however, find other avenues for their self-tracking or selfimprovement practices.

Surrogate support groups stress particular acceptable understandings of surrogacy in their processes of narrative co-construction. If a surrogate in such a group expresses doubts about surrogacy, other members help her 'regain her sense of purpose' (Ragoné 1994, 43). This idea of purpose recalls the quest narrative, but rather than the surrogate actively taking up her quest, it is other surrogates pushing her to return to it. Berend $(2016,32)$ demonstrates an example of how certain narratives are reinforced in online forums. One gestational surrogate responded to an intended mother considering traditional surrogacy - surrogacy using the surrogate's eggs - by telling her that the resulting baby would be a product of the intended mother's husband and the surrogate. Both intended mothers and surrogates in this online community responded to this comment with unanimous outrage and vehement disagreement. They stressed the dominant intended parent narrative that a baby born from surrogacy is the result of the love and planning of the intended parents rather than biology. This demonstrates that dominant intended parent narratives are also familiar to and accepted by surrogates, and shows how expressions which threaten the premises of the commercial surrogacy are quickly silenced in these group contexts. Because surrogacy has a marginal status within broader US society, surrogate programs, surrogates, and intended parents all have a vested interest in playing up the agency and altruism of surrogates and downplaying negative aspects such as tensions and disappointments in the relationship between parties (Ragoné 1994, 41; Teman 2010, 223). However, this restricts how those involved are able to portray their experiences, and it may be difficult to surrogates in particular to find alternative communities of support. 
The role of institutional power in the marginalisation of certain narratives occurs even more clearly in organ transplantation. Donor kin narratives position the donation as a meaningful way to maintain the altruistic spirit of their loved one, and telling these stories is experienced as an act of agency. However, Jensen $(2010,65)$ argues that this emphasis on making sense out of tragedy is also a narrative construction that is pushed on donor kin by transplantation organisations to further their goals of promoting donation. Positive donor kin stories are important tools in encouraging others to donate, while negative stories risk alienating potential donor families. As such, organ procurement organisations will train their donor kin volunteers in how to structure their stories and will provide them with phrases such as 'organs are gifts' and the donor is 'living on in spirit' to frame their storytelling in desired ways (Jensen 2010, 65). Donor kin might reveal any negative experiences of donation in private interviews, but there is little room for suffering or negativity in these public narratives (Jensen 2010, 67).

Organ recipients are heavily dependent on transplant institutions and groups, in the lead-up to their surgery and for post-transplant medical care and social support (Siminoff and Chillag 1999,36). Through their immersion in the world of organ transplantation, recipients are exposed to the dominant narratives of recipiency, which emphasise overcoming illness and gaining a 'new lease on life' (Kierans 2010, 37). Yet recipients must continue to take immunosuppressants and will likely experience various side effects or symptoms post-transplant (Sharp 2006, 107-108), a reality that is only hinted at in these narratives. Recipients may further experience employment difficulties, failed relationships, financial troubles, or depression due to these medical demands of post-transplant life (Sharp 2006, 119). Nevertheless, recipients often feel indebted for the 'gift' of their new organ, pushing them to participate in donation promotion. This involves publicly telling a personal story of rebirth, either in speeches at events or in one-on-one encounters at places like shopping centres (Siminoff and Chillag 1999, 39). The aims and norms of transplant organisations discourage discussion of negative aspects of transplantation in such storytelling, leaving little room for recipients to discuss their post-transplant struggles or prepare future recipients for such issues (Kierans 2010, 37; Siminoff and Chillag 1999, 39).

\section{CONCLUSION}

These three examples of organ transplantation, surrogacy, and the Quantified Self all speak to the complex role of personal narratives in both individual and collective attempts to normalise these technologies. Health technology 
narratives offer a vital avenue for health technology users to make sense of their experiences and reconstruct their identities, and relevant institutions and social groups comprising other users with similar experiences are particularly influential as a setting in which individuals learn to narrate their experiences. The dominant narratives which emerge from these social contexts tend to cast the technologies concerned in a positive light and downplay negative aspects of their use, in keeping with the interests of various parties involved to normalise and promote the technologies. These narratives also emphasise the agency of the technology users throughout their experiences. It is important to take seriously how telling these stories can help people to deal with disruptive experiences, while also recognising the social and institutional forces at play, and how these can further marginalise people who have negative experiences with the various technologies.

\section{NOTES}

1 Claire Black is studying an MA in social anthropology at the University of Auckland. Her research interests are digital technologies, medical anthropology, and LGBTQ youth.

Email: cbla247@aucklanduni.ac.nz

2 Terminology for the parties involved in surrogacy differs. I use 'surrogate' for the woman who carries the pregnancy and 'intended parents' for people who employ a surrogate to have their child.

3 Depending on the program, intended parents may include individuals or samesex couples, but all the ethnographic sources I use refer to programs which exclusively served heterosexual couples as intended parents.

\section{REFERENCES}

Ådahl, Susanne. 2013. 'When Death Enables Life: Incorporation of Organs from Deceased Donors in Finnish Kidney Recipients'. Mortality 18 (2):130-150.

Alkhatib, Ali. 2014. 'Quantified Self: Ethnography of a Digital Culture'. PhD diss., University of California, Irvine. https:/pdfs.semanticscholar.org/9611/ e74ffb87c6foccee356cefi74aaddec48cfi.pdf

Becker, Gay. 1998. Disrupted Lives: How People Create Meaning in a Chaotic World. Berkeley: University of California Press. 
Berend, Zsuzsa. 2016. “We are All Carrying Someone Else's Child!”: Relatedness and Relationships in Third-Party Reproduction'. American Anthropologist 118 (1):24-36.

Butterfield, Adam. 2012. 'Ethnographic Assessment of Quantified Self Meetup Groups'. MA thesis, San José State University, San José. www.sjsu.edu/anthropology/docs/projectfolder/Butterfield-Adam-project.pdf

Campbell, Joseph. 1968. The Hero with a Thousand Faces, 2nd edition. Princeton, NJ: Princeton University Press.

Charmaz, Kathy. 1999. 'From the "Sick Role" to Stories of Self: Understanding the Self in Illness'. In Self, Social Identity, and Physical Health Interdisciplinary Explorations, edited by Richard Contrada and Richard Ashmore, 209-239. Oxford: Oxford University Press.

Cussins, Charis. 1998. “Quit Sniveling Cryo-Baby, We'll Work Out Which One's Your Mama!'”. In Cyborg Babies: From Techno-sex to Techno-tots, edited by Robbie Davis-Floyd and Joseph Dumit, 40-66. New York: Routledge.

Das, Veena. 2007. Life and Words: Violence and Descent into the Ordinary. Berkeley: University of California Press.

Davis, Jenny. 2013. 'The Qualified Self'. Cyborgology, March 13. https://thesocietypages.org/cyborgology/2013/o3/13/the-qualified-self/

Eastmond, Marita. 2007. 'Stories as Lived Experience: Narratives in Forced Migration Research'. Journal of Refugee Studies 20 (2):248-264.

Fiore-Gartland, Brittany, and Gina Neff. 2015. 'Communication, Mediation, and the Expectations of Data: Data Valences Across Health and Wellness Communities. International Journal of Communication 9:1466-1484.

Fox, Renée C., and Judith P. Swazey. 1992. Spare Parts: Organ Replacement in American Society. Oxford University Press, UsA.

Frank, Arthur W. 1995. The Wounded Storyteller: Body, Illness, and Ethics. Chicago: University of Chicago Press.

Garro, Linda, and Cheryl Mattingly. 200o. 'Narrative as Construct and Construction'. In Narrative and the Cultural Construction of Illness and Healing, ed- 
ited by Cheryl Mattingly and Linda Garro, 1-49. Berkeley: University of California Press.

Goslinga-Roy, Gillian. 200o. 'Body Boundaries, Fiction of The Female Self: An Ethnographic Perspective on Power, Feminism, and the Reproductive Technologies'. Feminist Studies 26 (1):113-140.

Hogle, Linda. 1995. 'Tales from the Cryptic: Technology Meets Organism in the Living Cadaver'. In The Cyborg Handbook, edited by Chris Hables Gray, 203216. New York: Routledge.

Hsieh, Elaine. 2004. 'Stories in Action and the Dialogic Management of Identities: Storytelling in Transplant Support Group Meetings'. Research on Language and Social Interaction 37 (1):39-70.

Hunt, Linda. 200o. 'Strategic Suffering: Illness Narratives as Social Empowerment among Mexican Cancer Patients'. In Narrative and the Cultural Construction of Illness and Healing, edited by Cheryl Mattingly and Linda Garro, 88-107. Berkeley: University of California Press.

Jackson, Michael. 2002. The Politics of Storytelling: Violence, Transgression, and Intersubjectivity. Copenhagen: Museum Tusculanum Press.

Jensen, Anja. 2010. 'A Sense of Absence: The Staging of Heroic Deaths and Ongoing Lives among American Organ Donor Families'. In An Anthropology of Absence: Materializations of Transcendence and Loss, edited by Mikkel Bille, Frida Hastrup, and Tim Sørensen, 63-80. New York: Springer.

Kashmeri, Shireen. 2008. 'Unraveling Surrogacy in Ontario, Canada. An Ethnographic Inquiry on the Influence of Canada's Assisted Human Reproduction Act (2004), Surrogacy Contracts, Parentage Laws, and Gay Fatherhood'. MA thesis, Concordia University, Montreal, Quebec. http://spectrum.library. concordia.ca/975999/

Kierans, Ciara. 2010. 'Transplantation, Organ Donation and (In)Human Experience: Re-Writing Boundaries through Embodied Perspectives on Kidney Failure'. In Culture, Bodies and the Sociology of Health, edited by Elizabeth Ettore, 21-43. Burlington, VT: Ashgate.

Kleinman, Arthur. 1988. The Illness Narratives: Suffering, Healing, and the Human Condition. New York: Basic Books. 
Lupton, Deborah. 2013. 'Understanding the Human Machine [Commentary]'. IEEE Technology and Society Magazine 32 (4):25-30.

- 2016. The Quantified Self. Malden, MA: Polity.

Merino, Faith. 2010. Adoption and Surrogate Pregnancy. Infobase Publishing.

Nafus, Dawn, and Jamie Sherman. 2014. 'This One Does Not Go Up to 11: The Quantified Self Movement as an Alternative Big Data Practice'. International Journal of Communication 8:1784-1794.

Ochs, Elinor, and Lisa Capps. 1996. 'Narrating the Self'. Annual Review of Anthropology 25 (1): 19-43.

Ragoné, Helena. 1994. Surrogate Motherhood: Conception in the Heart. Boulder: Westview Press.

Ruckenstein, Minna, and Mika Pantzar. 2015. 'Datafied Life: Techno-Anthropology as a Site for Exploration and Experimentation'. Techne: Research in Philosophy and Technology. https://doi.org/10.5840/techne20159935

Sharon, Tamar. 2017. 'Self-Tracking for Health and the Quantified Self: Re-Articulating Autonomy, Solidarity, and Authenticity in an Age of Personalized Healthcare.' Philosophy and Technology 30 (1):93-121.

Sharon, Tamar, and Dorien Zandbergen. 2016. 'From Data Fetishism to Quantifying Selves: Self-Tracking Practices and the Other Values of Data'. New Media and Society 1-15. https://doi.org/10.1177/1461444816636090

Sharp, Lesley. 2006. Strange Harvest: Organ Transplants, Denatured Bodies and the Transformed Self. Berkeley: University of California Press.

-2007. Bodies, Commodities and Biotechnologies: Death, Mourning and Scientific Desire in the Realm of Human Organ Transfer. Columbia University Press.

Siminoff, Laura, and Kata Chillag. 1999. 'The Fallacy of the "Gift of Life”. Hastings Center Report 29 (6):34-41.

Strathern, Marilyn. 1992. Reproducing the Future: Essays on Anthropology, Kinship and the New Reproductive Technologies. Manchester, UK: Manchester 
Article $\cdot$ Black

University Press.

Teman, Elly. 2010. Birthing a Mother: The Surrogate Body and the Pregnant Self. Berkeley: University of California Press.

Trnka, Susanna. 2008. State of Suffering: Political Violence and Community Survival in Fiji. Ithaca, NY: Cornell University Press.

Wainwright, Bethli. 2011. 'Liver Transplant Recipients' Reflections on Organ Donors and Organ Donation: A Preliminary Analysis'. Sites (New Series) 8 (1): 83-107. 